\title{
CLIENTS' SATISFACTION WITH REFERRAL SYSTEM IN KARBALA
}

\author{
Ali A. Kadhim Abutiheen \\ Department of Family and Community Medicine, Karbala University, College of Medicine, Karbala, Iraq
}

Received 2013-09-13; Revised 2013-11-30; Accepted 2013-12-20

\begin{abstract}
Referral is a dynamic process and it had been recognized as crucial since the Alma Ata declaration in 1978. Hospitals are overcrowded with patients who could be more cheaply treated in smaller facilities is a common feature of poorly functioning Referral System (RS). Client Satisfaction (CS) is an important parameter in the assessment of health care quality. A descriptive cross sectional study conducted to measure CS with $\mathrm{RS}$ in Karbala province in Iraq. A special questionnaire based on 5 points Likert scale prepared for this purpose and been testes in a pilot study. T test were used to compare means of satisfaction. A total 726 clients from four hospitals and eight randomly selected Primary Health Care Centers (PHCCs) were interviewed. The mean age of the group was $33.4 \pm 9$ years and females form $56.3 \%$ of clients. CS with RS was $19 \%$ strongly satisfied, $45.7 \%$ satisfied, $7 \%$ fairly satisfied, $22.2 \%$ dissatisfied and $6.3 \%$ strongly dissatisfied. On a score of five the overall satisfaction with RS was $3.49 \pm 1.21$. Females had higher satisfaction with RS than males $(p=0.004)$, also PHCCs clients showed higher satisfaction than hospitals clients $(\mathrm{p}=0.009)$.
\end{abstract}

Keywords: Primary Health Care, Referral System, Client Satisfaction, Karbala, Iraq

\section{INTRODUCTION}

Primary Health Care (PHC) introduced as the best strategy for health service delivery by WHO and the PHC values to achieve health for all require health systems that: "Put people at the center of health care" (WHO, 2008). In many health systems, the general practitioner or primary health care gatekeeper role is considered a vital component of demand management, restricting access to secondary care based on identified need, thus restraining healthcare costs (Clarke et al., 2010). Health care systems are often designed to encourage caretakers to seek care first at the primary level and then be referred, if necessary, to a higher level of care (Cervantes et al., 2003).

Referral is a dynamic process (Jahn and de Brouwere, 2001), a functioning Referral System (RS) is a critical part of an appropriate health care delivery system (Font et al., 2002) and it had been recognized as crucial since the Alma Ata declaration in 1978 (Hussein et al., 2011). The development of effective patient RS is one of the important public health issues in developing countries (Omaha et al., 1998). Patients are referred to specialist care when investigation or therapeutic options are exhausted in primary care and more specialized care is needed (Grimshaw et al., 2005).

Hospitals are overcrowded with patients who could be more cheaply treated in smaller facilities is a common feature of poorly functioning RS (Stefanini, 1994). While the primary function of hospital is to provide complex clinical care to patients referred from lower levels (Hensher et al., 2006) and access to it should be through Primary Healthcare Centers (PHCCs), except for emergency cases where patients may access the hospital directly via the hospital's emergency department (Rasoulynejad, 2007). Care provided by specialists compared with that provided by generalists is more costly due to the addition of expensive tests and highly selective treatments (Guevara et al., 2011).

Strengthening of the RS would contribute to high standards of care by limiting over medicalization (Sweeney, 1994); also it is of particular importance in 
pregnancy and childbirth (Jahn and de Brouwere, 2001; Murray et al., 2001; Pembe et al., 2010). Many studies showed that nearly $5 \%$ of PHC visits include a referral (Forrest et al., 2002; 2006; Kordy et al., 1992).

Under optimum conditions, up to $85 \%$ of all patients can be treated at primary level (Gorgen et al., 2004), while Forrest et al. (2007) refers to that $63 \%$ to $82 \%$ of patients referred from primary care settings ultimately attend a consultation with the type of specialist to whom they were referred. On the other hand Simba et al. (2008) find that up to $72.5 \%$ of patients at hospital were selfreferral. Forrest et al. (2002) indicate that obtaining advice was by far the most common reason for referral and in some cases, physicians referred because patients requested to see a specialist.

Patient or Client Satisfaction (CS) has emerged as an increasingly important parameter in the assessment of health care quality (Bamidele et al., 2011) and it's an important issue both for evaluation and improvement of healthcare services (Ahmad et al., 2011). Also Sohrabi and Albalushi (2011) refered to that low CS is associated with lower trust in caregivers and greater chance of physician change results in lesser continuity of care. Consequences of low-perceived quality of care include poor compliance with treatment and advice, failure to pursue follow-up care and dissuading others from seeking care (Hansen et al., 2008).

CS is a very important part of any clinical practice therefore it is imperative to consistently undertake surveys in the community or facility to introduce better services (Ahmad et al., 2011). CS with PHC services has been measured in many countries with a wide range of methods including a questionnaire that was based on five-point Likert scale (Albalushi et al., 2012).

Karbala province and its center Holy Karbala City, (105 km to the southwest of Baghdad) is an ancient historic city, with a population of about 1.100 .000 people. Its well-known for having the shrine of Imam AlHussein (the grandson of Profit Mohamed) who had been murter with his brothers, sons and fellows in Karbala land in 7th century AC and every year tens of millions of Muslims visit the city, also the city host frequent big mass gathering (Millions Visit) each year including the Arbaeen visit which is almost the biggest annual mass gathering in the world, with more than ten millions person gathered in Karbala in last three years on 18th to 20th of Safar Arabic month.

In July 2008, after months of preparation RS was reactivated in Karbala by Karbala Health Directorate, few months before it reactivated all over Iraq by Ministry of Health $(\mathrm{MOH})$. At beginning of the implementation, there was strong opposition for RS by many clients and officials, that affects its performance and still there is some opposition.

This study aims to measure clients' satisfaction with Referral System and process in Karbala.

\section{MATERIALS AND METHODS}

A descriptive cross sectional study conducted. Patients or clients whom had been referred previously at least for one time were included in the study and been interviewed at the Primary Health Care Centers (PHCCs) or at referral hospitals and the questionnaire been filled. Mothers or accompanying persons of child patients were included also. A sample size of 710 (353 PHCC clients and 346 hospital clients) were calculated using Epi Info program version 7 , "sample size for population survey" depending on number of clients attending hospitals and PHCCs selected within 3 months from last year and an expected referral rate of $5 \%$.The sample size increased by $5 \%$ to overcome any refusal for participation.

The survey conducted for the period from 15th of October 2010 to 15th January 2011, a special questionnaire prepared for the purpose of the study based on direct interview with clients. It's composed of two parts, the first include socio-demographic data that include: Age, gender, residence (urban or rural), marital status, occupation and educational level. Second part include 12 closed ended question, based on 5 points Likert scale for evaluating opinion in regards to RS and performance of PHCCs and hospitals. Questionnaire had been tested by a pilot study included 20 clients that not included in final study, a little revision done and questionnaire finalized after been approved by two Community Medicine experts.

Twelve students from College of Medicine-Karbala University- 4th year class where trained on questionnaire filling, data collection and on how to make an interview and they perform the interview of clients, each interview take between 8-10 min to be completed.

Four hospitals of total 5 in Karbala and 8 major Primary Health Care Centers (PHCCs) randomly selected from the total 28 were included in the study (MOH, 2011), from all four Health Districts, in Karbala, taking in consideration the distance from hospitals. A small hospital and a PHCC in Ein-Altamr area were excluded as they were in remote rural region $(70 \mathrm{~km}$ away from Karbala).

Administrative approval on research conduction was obtained from Karbala University-College of Medicine and Karbala Health Directorate. Oral informed consent taken from each interviewee at beginning of interview and those whom refuse to participate in the study were excluded, so eight clients refuse to participate in the 
study (about $1 \%$ of total sample), clients whom not been referred previously were not included in the study.

Answers of five-point Likert scale for areas of satisfaction were coded as: Strongly satisfied: 5, satisfied: 4, fairly satisfied: 3 , dissatisfied: 2 and strongly dissatisfied: 1 ; then the mean of every area were estimated. Data presented and analyzed using SPSS program version 15, Student ttests were used for data analysis. $\mathrm{P}$ value less than 0.05 considered statistically significant.

\section{RESULTS}

A total 726 clients where interviewed, 369 PHCCs clients and 357 hospital clients, there mean age $33.37 \pm 13.01$ years with no significant difference between mean ages of PHCCs and hospitals clients.

Socio-demographic characteristics of the study group are shown in Table 1, $317(43.7 \%)$ males and 409 $(56.3 \%)$ females, $85 \%$ of them live in urban area. Regarding marital status (77\%) were married (20\%) were singles and $3 \%$ were widowed or divorced. For education; $15.4 \%$ had no or little education ( $<6$ years), $36 \%$ finish primary school (6-8years), $24.9 \%$ finish secondary school (9-11 years) and $23.7 \%$ had a higher education (>12 years). Concerning their occupation; housewives form $43.8 \%$ of them, workers $20.4 \%$, governmental employee $20 \%$ and other occupations including students and non-workers forms $15.8 \%$.

History of previous refer ranges 1-50 times, 466 $(64.2 \%)$ had been referred once previously 260 (35.8\%) been referred for more than one time, of those 3 clients indicated that they had been referred for more than 20 times previously.
The overall satisfaction of clients with referral system was $64.7 \%$ of (19\% strongly satisfied, $45.7 \%$ satisfied), on the other hand $28.5 \%$ where dissatisfied $(22.2 \%$ dissatisfied, $6.3 \%$ strongly dissatisfied), while those whom fairly satisfied forms 7\%, as shown in Fig. 1.

About $49 \%$ of clients indicate that they had some difficulties in referral and $65.4 \%$ of respondent indicate that they prefer to go directly to hospitals, while $34.6 \%$ prefer to go to PHCCs. More than $65 \%$ of clients where satisfied with PHCCs work and less than $11 \%$ of them were dissatisfied with its work and $74 \%$ of respondent believe that hospitals work better than PHCCs. On the other hand nearly $60 \%$ indicate presence of some shortage in PHCCs work and $45 \%$ indicate presence of some shortages in hospitals works. As an indicator of effectiveness of RS $88 \%$ indicate that they had the special family cards that been disseminated with the implementation of the program and $61 \%$ had the card with them. While just $66 \%$ knows that emergency cases do not require referral.

On a score of five the overall satisfaction with referral system was $3.49 \pm 1.21$. The mean age of the satisfied group was $32.86 \pm 13.32$ years while the mean age for non satisfied group was $35.19 \pm 12.1$ years and there was a significant statistical difference between the two means $(\mathrm{p}=0.032)$. Table 2 shows the relation between mean satisfaction with RS and certain variables. There was significant statistical difference $(\mathrm{p}<0.05)$ for gender where females shows higher mean of satisfaction than males and also it was significant for site of interview were PHCCs clients showed higher satisfaction mean than hospital clients. The mean satisfaction index shows no statistical significant difference in regards to residence, marital status, education level, occupation and number of previous refers.

Table 1. Socio-demographic characteristics of clients

\begin{tabular}{llcc}
\hline & Variable & No. of cases & Percentage \\
\hline Gender & Male & 317 & 43.7 \\
& Female & 409 & 56.3 \\
Residence & Urban & 628 & 86.5 \\
Marital status & Rural & 98 & 13.5 \\
& Single & 144 & 19.8 \\
\multirow{2}{*}{ Education } & Married & 559 & 77.0 \\
& Divorcedlwidow & 23 & 3.2 \\
& <6 years & 112 & 15.4 \\
\multirow{3}{*}{ Work } & 6-8 years & 261 & 36.0 \\
& 9-11 years & 181 & 24.9 \\
& $>12$ years & 172 & 23.7 \\
& Housewife & 318 & 43.8 \\
\hline
\end{tabular}


Ali A. Kadhim Abutiheen / American Journal of Applied Sciences 11 (2): 216-222, 2014

Table 2. The relation between mean satisfaction for referral system with different variables

\begin{tabular}{|c|c|c|c|c|c|}
\hline & Variable & $\begin{array}{l}\text { Number } \\
(\mathrm{N}=726)\end{array}$ & $\begin{array}{l}\text { Mean of } \\
\text { satisifaction }\end{array}$ & $\begin{array}{l}\text { Standerd } \\
\text { deviation }\end{array}$ & $\mathrm{P}$ value \\
\hline \multirow[t]{2}{*}{$\overline{\text { Gender }}$} & Male & 317.00 & 3.34 & 1.26 & 0.004 \\
\hline & Female & 409.00 & 3.60 & 1.16 & \\
\hline \multirow[t]{2}{*}{ Residance } & Urban & 98.00 & 3.32 & 1.34 & 0.128 \\
\hline & Rural & 628.00 & 3.52 & 1.18 & \\
\hline \multirow[t]{3}{*}{ Marital status } & Single & 144.00 & 3.54 & 1.16 & 0.477 \\
\hline & Married & 559.00 & 3.47 & 1.23 & \\
\hline & Divorced $/ w i d o w$ & 23.00 & 3.74 & 0.92 & \\
\hline \multirow[t]{4}{*}{ Education } & $<6$ years & 112.00 & 3.58 & 1.12 & 0.479 \\
\hline & $6-8$ years & 261.00 & 3.50 & 1.14 & \\
\hline & $9-11$ years & 181.00 & 3.53 & 1.24 & \\
\hline & $>12$ years & 172.00 & 3.37 & 1.33 & \\
\hline \multirow[t]{4}{*}{ Occupation } & Housewife & 318.00 & 3.58 & 1.16 & 0.269 \\
\hline & Worker & 148.00 & 3.43 & 1.18 & \\
\hline & Governmental employee & 145.00 & 3.35 & 1.35 & \\
\hline & Others & 115.00 & 3.50 & 1.19 & \\
\hline \multirow[t]{2}{*}{ Previous Refer } & Once & 466.00 & 3.50 & 1.20 & 0.694 \\
\hline & More & 260.00 & 3.47 & 1.23 & \\
\hline \multirow[t]{2}{*}{ Site of interview } & PHCC & 369.00 & 3.60 & 1.11 & 0.009 \\
\hline & Hospital & 357.00 & 3.37 & 1.29 & \\
\hline
\end{tabular}

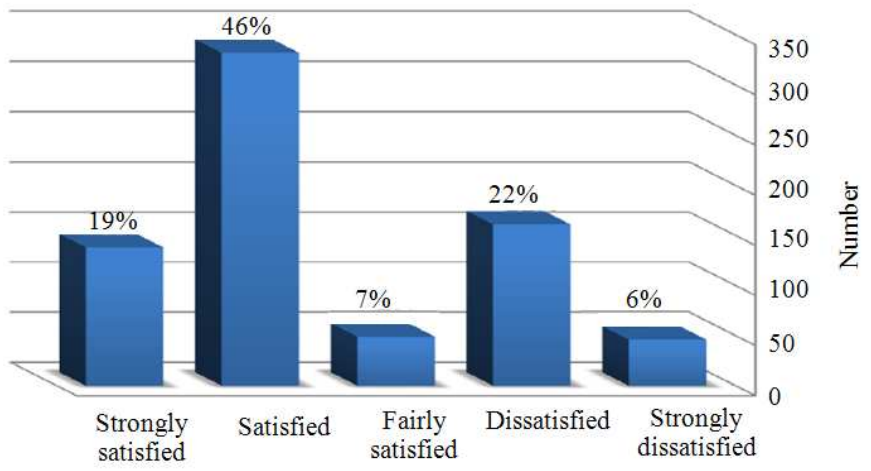

Fig. 1. The degree of clients' satisfaction with referral system

\section{DISCUSSION}

Surveys of client, patient, are an incresingly important issue that had evaluated for various areas of health and health services (Farzianpour et al., 2013; Abu-Dalbouh, 2013), also customer or user satisfaction Surveys are done in many sectores other than health for measuring performance of that sector (Hossain and Suchy, 2013; Lo, 2012; Balakrishnan et al., 2011; Najib et al., 2011; Sarlak and Fard, 2009; Larsen and Blair, 2009).

In this study, $56.3 \%$ of the interviewees were females and this was none surprising, as in Iraq females visit health facilities more than males, for their own health issues or for caring of their children and this goes with the $58 \%$ females rate of clients in Karbala in 2010
(MOH, 2011) and also with (Shabila et al., 2012; Albalushi et al., 2012; Damanhouri, 2011; Afsar and Younus, 2004; Sa'adoon et al., 2008) studies where females forms 52.4, 58, 62.5,62.8, 55.1\% respectively.

The mean age was $33.37 \pm 13.01$ years, this is older than the mean age of Albalushi et al. (2012) were the mean age was $27.5 \pm 8.3$ years and younger than (Afsar and Younus, 2004; Greenhow et al., 1998) where the mean ages were 37.5 and 43 years respectively.

In current study the majority of clients $(64.7 \%)$ were satisfied with the program and this is an important result, as no previous study done to estimate CS and this will help in pushing the implementation of RS foreword. AlTawil et al. (2011) find a satisfaction rate of $69.3 \%$ while in Greenhow et al. (1998) the satisfaction rate was 
$65.3 \%$ and these satisfaction rates are close to our result. On the other hand those who were not satisfied was $28.5 \%$ and this is less Afsar and Younus (2004) study were dissatisfied form $31.6 \%$.

The overall mean satisfaction with referral system on scale of 5-points was 3.49 and this goes with the study of Mansour and Al-Osaimi (1993) were the satisfaction was 3.55 .

There was a significant association between satisfaction with RS and age, where younger age appear to be more satisfied with RS. This result is different than other studies that shows an association between satisfaction with increasing age (Jiang et al., 2009; Greenhow et al., 1998). Also there was significant association with gender as females shows higher satisfaction than males. Pappa et al. (2013) find the opposite, while Sa'adoon et al. (2008) and Sohrabi and Albalushi (2011) found higher satisfaction with health services among females but it wasn't statistically significant. Last two studies find significant association between level of satisfaction and lower education levels, although this study shows similar relation but it was not statistically significant. Other socio-demographic characteristics shows no significant association.

Also there was no statistical difference in satisfaction between those who were referred previously once and those referred frequently. The satisfaction among PHCCs clients was significantly higher than that for Hospitals clients and this could be explained by that hospital clients were more used to go to hospitals directly and to be more oppositional to referral system and this could be obvious as $65 \%$ of clients in this study indicate that they prefer to go directly to hospitals.

Hooper et al. (2005) indicates that it is common for doctors not to write a prescription or make a referral which patients were expecting and these unmet expectations are associated with increased patient dissatisfaction. Similar issues seems to decrease the satisfaction of clients with RS, as they used to visit hospitals directly for years without a need for a referral from a PHCC and as majority believe that hospitals work better, have better investigations, medications, diagnostic tools and more specialized doctors in it.

\section{CONCLUSION}

Referral system is an essential program in health services delivery and its implementation in Karbala and Iraq, though facing some opposition from many groups but it is accepted by majority of clients. More efforts needed to improve the program, by supporting the
PHCCs, increasing awareness about program such as emergency cases non-inclusion and supporting feedback from the hospitals. Further studies are needed to explore other aspects of program, PHCCs work and client satisfactions with different health services.

\section{ACKNOWLEDGEMENT}

I would like to thank, the group of fourth year class, whom participate in conducting the interviews with clients and as they actually had been graduated right now, I wish they got good experience that will help them in their future work.

\section{REFERENCES}

Abu-Dalbouh, H.M., 2013. A questionnaire approach based on the technology acceptance model for mobile tracking on patient progress applications. J. Comput. Sci., 9: 763-770. DOI: 10.3844/jcssp.2013.763.770

Afsar, H.A. and M. Younus, 2004. Patient referral at the grass-roots level in Pakistan. Nat. Sci., 2: 18-27.

Ahmad, I., A. Nawaz, S. Khan, H. Khan and M. A. Rashid, 2011. Predictors of patient satisfaction. Gomal J. Med. Sci., 9: 183-188. PMID: 11206657

Albalushi, R.M., M.R. Sohrabi and A.A. Kolahi, 2012. Clients' satisfaction with primary health care in muscat. Int. J. Preventive Med., 3: 713-717. PMID: 23112898

Al-Tawil, N.G., M. Wahab and N. Shabila, 2011. Assessment of the primary care referral system in Iraqi Kurdistan. Proceedings of the International Congress on Reform and Development of Health Care System in Kurdistan Region, Feb. 2-4, Erbil, Iraq.

Balakrishnan, V., P.H.P. Yeow and H.S. Loo, 2011. An empirical analysis on mobile phone messaging satisfaction among Malaysian youths. J. Soc. Sci., 7: 241-250. DOI: 10.3844/jssp.2011.241.250

Bamidele, A., M. Hoque and H. Van der Heever, 2011. Patient satisfaction with the quality of care in a primary health care setting in Botswana. South African Fam Pract, 53: 170-175.

Cervantes, K., R. Salgado, M. Choi and H.D. Kalter, 2003. Rapid assessment of referral care systems: A guide for program managers. Proceedings of the Published by the Basic Support for Institutionalizing Child Survival Project (ICS '03), Arlington, Virginia. 
Clarke, A., N. Blundell, I. Forde, N. Musila and D. Spitzer, 2010. Can guidelines improve referral to elective surgical specialties for adults? A systematic review. Q. Saf. Health Care, 19: 187-194. DOI: 10.1136/qshc.2008.029918

Damanhouri, M.S.A., 2011. The level of satisfaction of the health services offered by the comprehensive health care center. J. Soc. Sci., 7: 516-520. DOI: 10.3844/jssp.2011.516.520

Farzianpour, F., L. Godarzi, A.T. Hamedani, R. Askari and S.S. Hosseini, 2013. Evaluation of customer relationship management in a teaching hospital. Am. J. Applied Sci., 10: 344-352. DOI: 10.3844/ajassp.2013.344.352

Font, F., L. Quinto, H. Masanja, R. Nathan and C. Ascaso, 2002. Paediatric referrals in rural Tanzania: The kilombero district study-a case series. BMC Int. Health Hum. Rights, 2: 4-4. DOI: 10.1186/1472698X-2-4

Forrest, C.B., E. Shadmi, P.A. Nutting and B. Starfield, 2007. Specialty referral completion among primary care patients: Results from the ASPN referral study. Annals Family Med., 5: 361-367. DOI: 10.1370/afm.703

Forrest, C.B., P.A. Nutting, B. Starfield and S.V. Schrader, 2002. Family physicians' referral decisions: Results from the ASPN referral study. J. Family Pract., 51: 215-222. PMID: 11978231

Forrest, C.B., P.A. Nutting, S. Schrader, C. Rohde and B. Starfield, 2006. Primary care physician specialty referral decision making: Patient, physician and health care system determinants. Med. Decision Mak., 26: 76-85. DOI: 10.1177/0272989X05284110

Gorgen, H., T. Kirsch-Woik and B. Schmidt-Ehry, 2004. The District Health System: Experiences and Prospects in Africa. Wiesbaden, Deutsche Gesellschaft für Technische Zusammenarbeit (GTZ) $\mathrm{GmbH}$.

Greenhow, D., A.J. Howitt and P. Kinnersley, 1998. Patient satisfaction with referral to hospital: Relation-ship to expectations, involvement and information-giving in the consultation. British $\mathrm{J}$. General Pract., 48: 911-912. PMD: 9604417

Grimshaw, J., R. Winkens, L. Shirran, C. Cunningham and A. Mayhew, 2005. Interventions to improve outpatient referrals from primary care to secondary care. Cochrane Database Syst. Rev., 20: CD005471CD005471. PMID: 16034981
Guevara, J.P., D. Hsu and C.B. Forrest, 2011. Performance measures of the specialty referral process: A systematic review of the literature. BMC Health Services Res., 11: 168-168. DOI: 10.1186/1472-6963-11-168

Hansen, P.M., D.H. Peters, K. Viswanathan, K.D. RAO and A. Mashkoor, 2008. Client perceptions of the quality of primary care services in Afghanistan. Int. J. Q. Health Care, 20: 384-391.

Hensher, M., M. Price and S. Adomakoh, 2006. Referral Hospitals, in Disease Control Priorities in Developing Countries. In: A Copublication of Oxford Universi-ty Press and The World Bank, Jamison, D.T., J.G. Breman, A.R. Measham, G. Alleyne and M. Claeson et al. (Eds.), ISBN-10: 08213-0821361791, pp: 1229-1243.

Hooper, R., R.J. Rona, C. French, M. Jones and S. Wessely, 2005. Unmet expectations in primary care and the agreement between doctor and patient: A questionnaire study. Health Expect., 8: 26-33. PMID: 15713168

Hossain, M.M. and N.J. Suchy, 2013. Influence of customer satisfaction on loyalty: A study on mobile telecommunication industry. J. Soc. Sci., 9: 73-80. DOI: $10.3844 /$ jssp.2013.73.80

Hussein, J., L. Kanguru, M. Astin and S. Munjanja, 2011. What kinds of policy and programme interventions contribute to reductions in maternal mortality? The effectiveness of primary level referral systems for emergency maternity care in developing countries. International Initiative for Impact Evaluation.

Jahn, A. and V. de Brouwere, 2001. Referral in Pregnancy and childbirth. Concepts and Strategies.

Jiang, L., C. Gan, B. Kao, Y. Zhang and H. Zhang et al., 2009. Consumer satisfaction with public health care in China. J. Soc. Sci., 5: 223-235. DOI: 10.3844/jssp.2009.223.235

Kordy, M.N., M.A. Ibrahim, F.M. Al-Gamal, A. Bahnassy and W. Milaat, 1992. A study of the morbidity pattern of referred patients and the effectiveness of the refer-ral system in primary health care centers. J. Egyptian Public Health Assoc., 67: 709-724. PMID: 1294691

Larsen, J.E. and J.P. Blair, 2009. The importance of police performance as a determinant of satisfaction with police. Am. J. Econ. Bus. Admin., 1: 1-10. DOI: 10.3844/ajebasp.2009.1.10 
Lo, S.C., 2012. A study of relationship marketing on customer satisfaction. J. Soc. Sci., 8: 91-94. DOI: 10.3844/jssp.2012.91.94

Mansour, A.A. and M.H. Al-Osaimi, 1993. A study of satisfaction among primary health care patients in Saudi Arabia. J. Community Health, 18: 163-173. PMID: 8408747

$\mathrm{MOH}$, 2011. Annual Report for 2010. Ministry of Health, Iraq.

Murray, S.F., S. Davies, R.K. Phiri and Y. Ahmed, 2001. Tools for monitoring the effectiveness of dis-trict maternity referral systems. Health Policy Plann., 16: 353-361. DOI: 10.1093/heapol/16.4.353

Najib, N.U.M., N.A. Yusof and Z. Osman, 2011. Measuring satisfaction with student housing facilities. Am. J. Eng. Applied Sci., 4: 52-60. DOI: 10.3844/ajeassp.2011.52.60

Omaha, K., V. Melendez, N. Uehara and G. Ohi, 1998. Study of a patient referral system in the Republic of Honduras. Health Policy Plann., 13: 433-445. PMID: 10346035

Pappa, E., N. Kontodimopoulos, A. Papadopoulos, Y. Tountas and D. Niakas, 2013. Investigating unmet health needs in primary health care services in a representative sample of the greek population. Int. J. Environ. Res. Public Health, 10: 2017-2027. DOI: 10.3390/ijerph10052017

Pembe, A.B., A. Carlstedt, D.P. Urassa, G. Lindmark and L. Nystrom., 2010. Effectiveness of maternal referral system in a rural setting: A case study from Rufiji district, Tanzania. BMC Health Services Res., 10: 326-326. DOI: 10.1186/1472-6963-10-326
Rasoulynejad, S., 2007. Patient views for self-referral to specialists. Iranian J. Public Health, 36: 62-67.

Sa'adoon, A.A., A.H. Hussien and T.R. Museher, 2008. Patients' satisfaction for health care services at Thiqar province, Iraq. Thi-Qar Med. J., 2: 39-45.

Sarlak, M.A. and R.S. Fard, 2009. The impact of CRM on the customer satisfaction in agricultural bank. Am. J. Econ. Bus. Admin., 1: 167-172. DOI: 10.3844/ajebasp.2009.167.172

Shabila, N.P., N.G. Al-Tawil, M.A. Wahab, T.S. AlHadithi and E. Sondorp, 2012. Assessment of the Iraqi primary care referral system: Reporting a high self-requested referral rate. Middle East J. Family Med., 10: 4-10.

Simba, D.O., N.A.A. Mbembati, L.M. Museru and L.E. Lema, 2008. Referral pattern of patients received at the national referral hospital: Challenges in low income countries. East African J. Public Health, 5: 69.

Sohrabi, M.R. and R.M. Albalushi, 2011. Clients' Satisfaction with primary health care in Tehran: A cross-sectional study on iranian health centers. J. Res. Med. Sci., 16: 756-762.

Stefanini, A., 1994. District hospitals and strengthening referral systems in developing countries. World Hosp Health Serv., 30: 14-19. PMID: 10142968

Sweeney, B., 1994. The referral system. BMJ, 309: 1180-1181. PMCID: PMC2541708

Sweeney, B., 1994. The referral system. BMJ, 309: 1180-1181. DOI: 10.1136/bmj.309.6963.1180

WHO, 2008. The World Health Report 2008-Primary Health Care (Now More Than Ever). World Health Organization, Geneva. 